\title{
SOSIALISASI UPAYA PEMBASAHAN LAHAN GAMBUT DENGAN PEMBANGUNAN SUMUR BOR SECARA PARTISIPATIF
}

\author{
Henny Herawati ${ }^{1)}$, Kartini ${ }^{1}$, Aji Ali Akbar $^{2)}$, Tatang Abdurrahman ${ }^{3)}$ \\ 1)Jurusan Teknik Sipil, Fakultas Teknik, Universitas Tanjungpura, Pontianak, Kalimantan Barat, Indonesia \\ 2) Jurusan Teknik Lingkungan, Fakultas Teknik, Universitas Tanjungpura, Pontianak, Kalimantan Barat, Indonesia \\ 3) Jurusan Agroteknologi, Fakultas Pertanian, Universitas Tanjungpura, Pontianak, Kalimantan Barat, Indonesia \\ Corresponding author : Henny Herawati \\ E-mail : hennyherawati@civil.untan.ac.id
}

\section{Diterima 20 Oktober 2020, Direvisi 31 Oktober 2020, Disetujui 01 November 2020}

\begin{abstract}
ABSTRAK
Pada musim kemarau lahan gambut sering mengalami kekeringan. Kondisi kering dapat menyebabkan lahan gambut mudah terbakar. Untuk menjaga lahan gambut dari kondisi kering, maka perlu dilakukan upaya pembasahan lahan gambut. Saat musim kemarau ketersedian air permukaan sulit diperoleh. Sumber air yang dapat diandalkan adalah air tanah. Pengambilan air tanah baik dan terkendali, perlu dilakukan dengan pengetahuan dan teknologi sederhana. Hal ini diperlukan agar pembasahan lahan gambut dapat dilakukan secara partisipatif. Untuk mencapai tujuan, maka dilakukan upaya sosialisasi tentang metode pembuatan sumur bor yang dapat dilakukan oleh masyarakat secara partisipatif. Sosialisasi ini merupakan salah satu kegiatan pengabdian kepada msayarakat (PKM) yang dilakukan oleh Tim Pelaksana, dengan pendanaan dari Kementerian Riset, Teknologi dan Pendidikan Tinggi Tahun 2019. Kegiatan PKM ini dilakukan di Desa Wajok Hilir Kecamatan Siantan Kabupaten Mempawah Provinsi Kalimantan Barat. Kegiatan ini diawali dengan melakukan indept interview untuk mengali permasalahan di lokasi kegiatan. Sosialisasi dilakukan dengan metode ceramah dan praktek lapangan dengan melibatkan masyarakat setempat. Masyarakat sangat antusias mengikuti sosialisasi. Dampak kegiatan adalah meningkatnya kesehatan lingkungan dan masyakat serta dapat sebagai sumber air baku untuk keperluan sehari-hari. Kegiatan ini juga memberi dampak peningkatan pengetahuan dan kemampuan masyarakat setempat khususnya, dan diharapkan dapat menyebarluaskan informasi kepada masyarakat luas.
\end{abstract}

Kata kunci: lahan gambut; kekeringan, sumur bor; partisipatif; wajok hilir.

\begin{abstract}
The peatlands often experience drought in the dry season. Dry conditions can cause peatlands to burn easily. It is necessary to make efforts to wet the peatlands to protect peatlands from dry conditions. During the dry season, it is difficult to obtain surface water. A reliable source of water is groundwater. The extraction of groundwater is good and controlled, it needs to be done with simple knowledge and technology. This is necessary so that the wetting of the peatlands can be done in a participatory manner. To achieve the goal, an effort was made to socialize the method of making boreholes that can be done by the community in a participatory manner. This socialization is one of the community service (PKM) carried out by the implementation team, with funding from the Ministry of Research, Technology, and Higher Education in 2019. This PKM activity was carried out in Wajok Hilir Village, Siantan District, Mempawah Regency, West Kalimantan. This activity begins with conducting an in-depth interview to multiply the problems at the location of the activity. The socialization was carried out by lecturing methods and field practice involving the local community. The community was very enthusiastic about participating in the socialization. The impact of these activities is to improve the health of the environment and the community as well as to serve as a source of raw water for daily needs. This activity also has an impact on increasing the knowledge and capacity of the local community in particular, and it is hoped that it can disseminate information to the wider community.
\end{abstract}

Keywords: peatlands; drought, boreholes; participatory; wajok hilir.

\section{PENDAHULUAN}

Provinsi Kalimantan Barat didominasi oleh lahan basah, terutama lahan gambut. Lahan gambut secara alami merupakan lahan penyimpan air pada musim penghujan, sehingga dapat sebagai pengendali banjir. Namun pada musim kemarau, lahan gambut akan mengeluarkan air, mengisi lahan-lahan 
yang kekurangan air. Secara alami lahan gambut dapat berfungsi sebagai pengendali banjir dan kekeringan. Kondisi alami ini akan berubah jika terjadi perubahan hidrologis gambut tersebut. Perubahan hidrologis gambut dapat disebabkan dengan dibukanya lahan tersebut untuk dimanfaatkan. Pemanfaatan lahan gambut menyebabkan terjadinya perubahan tata guna lahan, misalnya lahan gambut alami berubah sebagai lahan pemukiman, pertanian atau perkebunan.

Pembukaan lahan gambut sebagai lahan pertanian biasanya dilengkapi dengan pembangunan saluran-saluran drainase untuk mengeluarkan air dari lahan. Pengeluaran air yang tak terkendali dapat menyebabkan tanah gambut berubah karakteristiknya dan tidak lagi dapat menjaga fungsinya secara optimal. Akibat dari perubahan karakateristik tanah gambut ini, maka pada musim penghujan sering terjadi banjir dan sebaliknya pada musim kemarau akan mengalami kekeringan. Kondisi ini terjadi hampir pada sebagian besar lahan gambut di Kalimantan Barat. Pada musim kemarau, kekeringan terjadi akan menyebabkan lahan mudah terbakar (Herawati et al., 2018).

Kebakaran hutan dan lahan (karhutla) merupakan peristiwa tahunan yang sering terjadi pada musim kemarau. Dampak karhutla yaitu rusaknya tanah, gambut, hilangnya plasma nutfah, dan besarnya emisi karbon yang ditimbulkan, serta asap menyebabkan gangguan kesehatan khususnya anak-anak dan lansia. Kebakaran lahan gambut lebih berbahaya dibanding kebakaran lahan mineral. Hal ini karena pada musim kemarau lapisan serasah dan gambut di bawah vegetasi di permukaan lahan juga mudah terbakar, sehingga lebih sulit dikendalikan (Badan_Penelitian_Dan_ Pengembangan_Pertanian, 2014). Selain itu, asap kebakaran lahan gambut menghasilkan 3-6 kali lebih banyak partikel dibanding kebakaran pada jenis tanah lainnya (World_Bank_Group, 2015). Oleh karena itu, diperlukan tindakan preventif maupun kuratif untuk mengurangi kerugian akibat kebakaran lahan gambut.

Kebakaran lahan gambut di Provinsi Kalimantan Barat merupakan peristiwa musiman yang telah dapat diprediksi namun masih sulit diatasi. Salah satu hal yang menyebabkan kebakaran sulit diatasi yaitu peristiwa kebakaran terjadi di luasan dan dalam periode yang berbeda-beda tiap tahunnya. Dapat disimpulkan bahwa seluruh lahan gambut rentan mengalami kebakaran lahan. Kebakaran lahan tidak hanya disebabkan oleh musim kemarau yang berkepanjangan, melainkan disebabkan oleh rendahnya kadar air pada lahan gambut tersebut yang menyebabkan api semakin mudah menyebar dan sulit dipadamkan (Herawati et al. 2018).

Salah satu upaya penyediaan air pada musim kemarau dengan pembangunan infrastruktur pembasahan gambut berupa sumur bor. Sumur bor beserta sarana operasionalnya merupakan sumber air yang dapat diandalkan, meskipun musim kemarau. Air yang tersedia pada sumur bor dapat membasahi lahan gambut, saat tidak terjadi hujan atau musim kemarau. Air sumur juga dapat digunakan oleh masyakarat guna memenuhi kebutuhan sehari-hari.

Pengambilan air tanah dengan baik dan terkendali, perlu dilakukan dengan pengetahuan dan teknologi sederhana. Hal ini diperlukan agar masyarakat mudah melakukannya secara mandiri. Sehingga kegiatan pembasahan lahan gambut dapat dilakukan secara partisipatif oleh masyarakat. Untuk mencapai tujuan, maka dilakukan upaya sosialisasi tentang bagaimana metode pembuatan sumur bor yang benar, yang dapat dilakukan oleh masyarakat secara partisipatif dengan teknologi yang mudah dan biaya yang murah.

Tujuan dari kegiatan ini adalah untuk melakukan edukasi kepada masyarakat tentang metode pembangunan sumur bor, sehingga masyarakat dapat membuat sumur bor sendiri, guna melakukan upaya pembasahan lahan gambut secara partisipatif.

\section{METODE}

Metode yang dilakukan pada kegiatan ini adalah dengan metode ceramah dan praktek lapangan. Kegiatan dilakukan dengan melibatkan Mitra dan masyarakat secara langsung, baik pada saat ceramah maupun pada saat praktek pembuatan sumur bor sebagai percontohan. Mitra dari kegiatan merupakan warga Dusun Kopi Desa Wajok Hilir.

Kegiatan PKM ini dilakukan di Desa Wajok Hilir Kecamatan Siantan Kabupaten Mempawah Provinsi Kalimantan Barat. Lokasi Desa berbatasan langsung dengan lbu Kota Provinsi Kalimantan Barat yaitu Kota Pontianak. Keberadaan yang bersebelahan langsung ini, menyebabkan Desa Wajok Hilir, merupakan Desa yang strategis untuk dilakukan kegiatan PKM ini, mengingat dampak polusi udara seperti asap, jika terjadi kebakaran hutan akan sangat mengganggu kesehatan masyarakat Kota Pontianak, sekaligus merupakan pusat perekonomian di Kalimantan Barat. 
Kegiatan PKM ini diawali dengan melakukan indept interview untuk mengali permasalahan di lokasi kegiatan. Setelah mengetahui permasalahan utama pada lokasi PKM, dilakukan sosialisasi kepada masyarakat sebagai Mitra kegiatan PKM. Sosialisasi diikuti oleh sekitar 40 Warga Desa Wajok Hilir.

Setelah dilakukan sosialisasi dengan metode ceramah dilakukan praktek lapangan, yaitu dengan metode demonstrasi partisipatif. Kegiatan praktek lapangan dibimbing oleh tenaga terampil yang disediakan oleh Tim Pelaksana. Tenaga terampil bersama-sama masyarakat sebagai volunteer melaksanakan pembangunan sumur bor, yang disaksikan oleh masyarakat yang lain, untuk mengetahui metode pelaksanaan pembangunan sumur bor.

Setelah selesai pembangunan sumur bor, juga dilanjutkan dengan memberikan pengetahuan kepada masyarakat sebagai Mitra PKM tentang cara pengoperasian dan pemeliharaan sumur bor.

\section{HASIL DAN PEMBAHASAN \\ Permasalahan Lahan Gambut}

Lahan gambut di Desa Wajok Hilir dimanfaatkan oleh masyarakat setempat sebagai areal pemukiman dan lahan pertanian. Upaya pertanian sudah dilakukan sejak lama di Desa ini. Hal ini juga ditunjukan dengan penamaan dusunnya diambil dari nama-nama hasil pertanian yang menonjol di Desa tersebut, misalnya Dusun kopi, dusun nanas, dusun palawijaya dan beberapa dusun lainnya. Kondisi lahan gambut di Desa Wajok Hilir dapat dilihat pada Gambar 1.

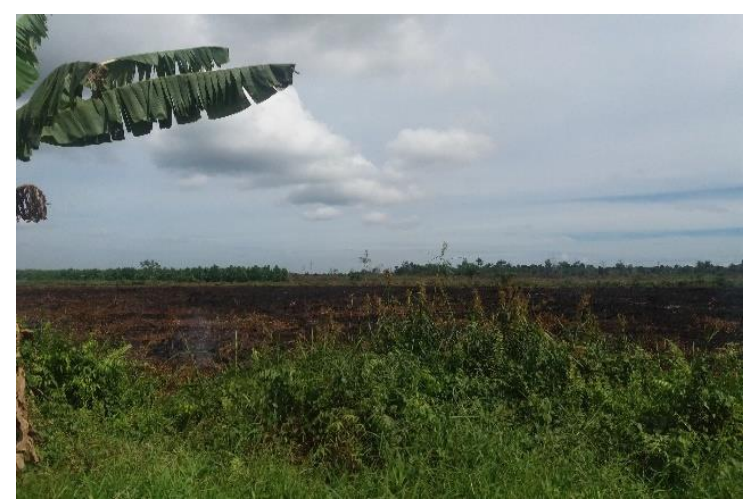

Gambar 1. Kondisi Lahan Gambut di Desa Wajok Hilir (Dokumentasi, 28 Februari 2018).

Dari wawancara terhadap masyarakat setempat, diketahui permasalahan utama pada musim kemarau adalah kurangnya sumber air yang dapat diperoleh warga untuk melakukan pembasahan lahan gambut. Dokumentasi kegiatan indept interview dapat dilihat pada Gambar 2.

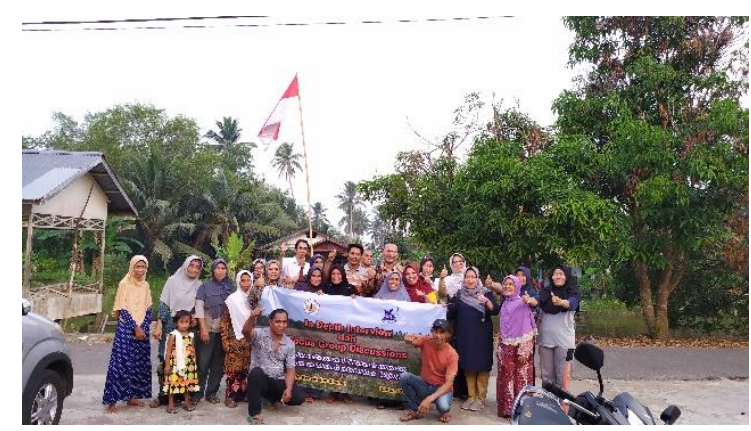

Gambar 2. Dokumentasi indept interview Bersama Warga Desa Wajok Hilir.

Masyarakat sudah pernah mencoba membuat sendiri sumur bor, namun terjadi kegagalan berupa keluarnya gas dari dalam tanah. Sehingga masyarakat tidak pernah dan berani lagi untuk mencobanya. Sumur yang pernah dibuat kembali ditutup oleh masyarakat (Herawati et al., 2019).

Untuk mengatasi kendala ini, maka tim menyediakan tenaga terampil yang dapat menunjukkan atau mendemontrasikan dan mengajarkan kepada masyarakat secara langsung bagaimana metode pembuatan sumur bor yang baik dan benar.

\section{Sosialisasi Kepada Masyarakat}

Dalam upaya memberikan dan meningkatkan pengetahuan dan pemahaman masyarakat tentang pembasahan lahan gambut dilakukan upaya pemberian sosialisasi dengan metode ceramah. Materi yang disampaikan berupa karakteristik dan tipologi lahan gambut, kualitas dan cara pengelolaanya.

Pengetahuan kegunaan untuk tetap menjaga gambut dalam keadaan basah dan apa kelebihannya, juga perlu disampaikan kepada masyarakat. Sehingga masyarakat dapat mengetahui manfaat yang dapat dirasakan oleh masyarakat Desa khususnya, maupun masyarakat umum yang dapat terkena dampak akibat kekeringan lahan gambut.

Sosialisasi juga diberikan langsung dengan cara mempraktekkan atau mendemonstrasikan cara pembuatannya. Hal ini dilakukan agar masyarakat dapat membuat sumur bor secara mandiri dengan swadaya masyarakat sehingga masyarakat dapat berperan aktif secara langsung. Suasana sosialisasi tentang pembasahan lahan gambut dapat dilihat pada Gambar 3. Suasana praktek lapangan sebagaimana yang ditunjukkan pada Gambar 4.

Dalam pelaksanaan PKM ini juga melibatkan mahasiswa untuk menambah pengalaman mahasiswa berkomunikasi kepada masyarakat dan menambah wawasan keilmuan dalam bidang sumber daya air khususnya pembangunan sumur bor. 


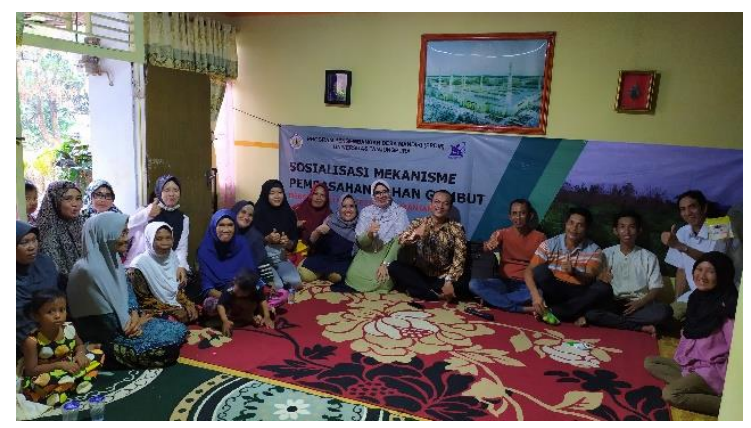

Gambar 3. Foto Bersama Masyarakat Pada Acara Sosialisasi.

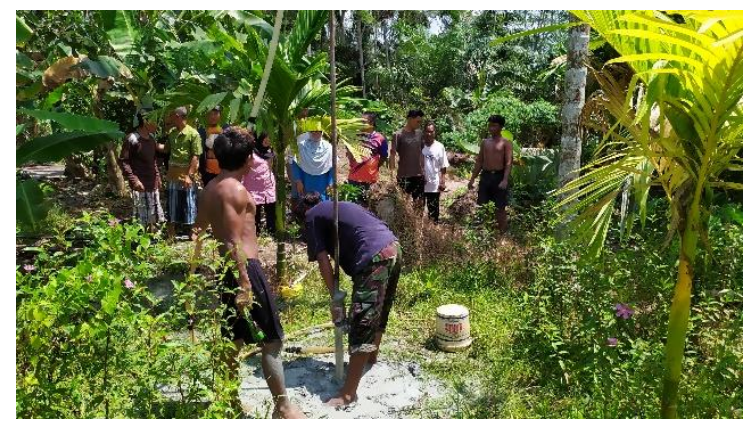

Gambar 4. Suasana Praktek Lapangan Bersama Masyarakat.

\section{Pembangunan Sumur Bor}

Sumur bor dibangun hingga mencapai akuifer bebas (Dohong et al., 2018). Kedalaman akuifer tidak sama pada lokasi yang berbeda. Secara umum, sumur bor terdiri atas pipa penyedot dan pipa casing. Spesifikasi tersebut merupakan hasil evaluasi dari pelaksanaan pembangunan sumur bor yang pernah dilakukan tim pelaksana sebelumnya. Dengan menggunakan pipa casing, maka material padat di dalam akuifer tidak ikut keluar dari sumur. Profil konstruksi sumur bor dapat dilihat pada Gambar 5.

Pada kegiatan ini, selain pembuatan sumur, telah dilakukan pula pengujian sumur hingga ditemukan air dari aquifer, perakitan alat bersama masyarakat. Pada lokasi kegiatan sumur bor mencapai kedalaman sekitar 60 meter. Setelah melalui proses pembangunan diperoleh sumber air bersih. Hasil pengambilan air tanah dapat dilakukan dengan baik dan lancar. Instalasi sumur bor yang sudah dibangun dapat dilihat pada Gambar 6 .

Evaluasi juga dilakukan terhadap kualitas air sumur. Dari pengamatan lapangan diketahui air sumur dapat digunakan sebagai air baku, hanya saja pengolahan terlebih dahulu. Hal ini disebabkan air sumur pada lahan gambut dipengaruhi oleh kualitas tanah gambut. Dimana kadar parameter besi berada di atas ambang standar baku mutu air bersih. Namun jika digunakan sebagai sumber air untuk pembasahan lahan gambut, tidak ada dampaknya.

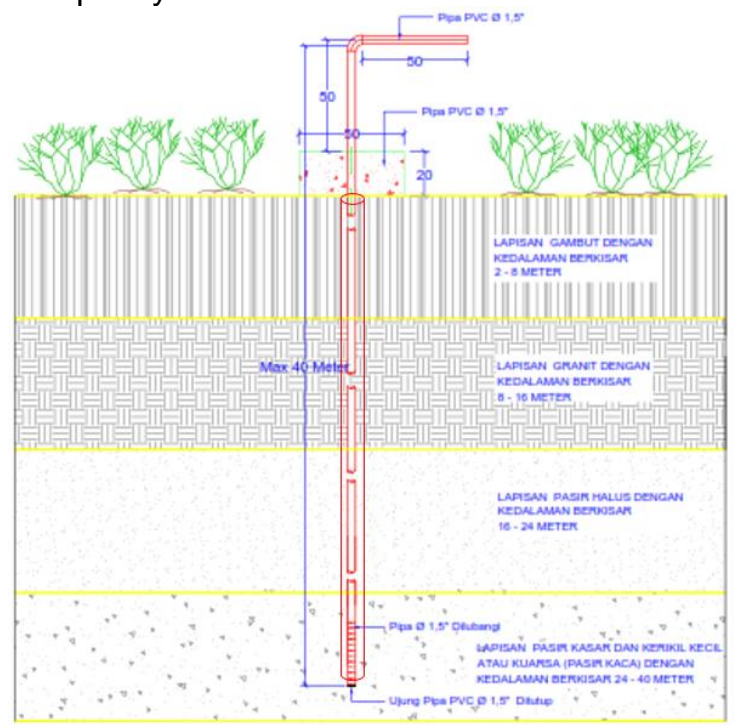

Gambar 5. Profil Konstruksi Sumur Bor

Umumnya untuk memperoleh hasil yang baik, air gambut dapat diolah dengan metode kuogulasi-flokulasi-sedimentasi (Suherman and Sumawijaya, 2013). Pengolahan air gambut ini juga diberikan informasinya kepada masyarakat Desa Wajok Hilir.

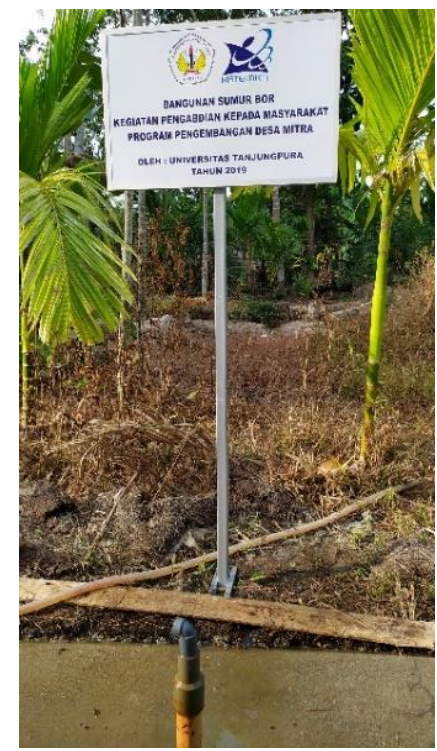

Gambar 6. Bangunan Sumur Bor di Desa Wajok Hilir

Dari kegiatan ini dihasilkan luaran tambahan berupa peningkatan keterampilan Mitra di Desa Wajok Hilir, dalam hal ini khususnya Kelompok Masyarakat Peduli Api/Gambut maupun kelompok tani yang memerlukan sumur untuk keperluan pembasahan lahan. 


\section{SIMPULAN DAN SARAN Simpulan}

Masyarakat sangat antusias mengikuti sosialisasi. Luaran dari kegiatan PKM yang telah dilakukan ini adalah meningkatnya kesehatan lingkungan dan masyarakat serta dapat sebagai sumber air baku untuk keperluan sehari-hari. Kegiatan ini juga memberi luaran peningkatan pengetahuan dan kemampuan masyarakat setempat khususnya, dan diharapkan dapat menyebarluaskan informasi kepada masyarakat luas.

\section{Saran}

Berdasarkan pengalaman dan capaian yang dirasakan oleh masyarakat, disarankan pelaksanaan PKM seperti ini dapat dilakukan pada tempat yang lain. Informasi serupa dapat disampaikan kepada masyarakat umumnya, dan khusunya masyarakat yang berada pada lahan gambut.

\section{UCAPAN TERIMAKASIH}

Terima kasih disampaikan kepada semua pihak yang telah membantu dalam pelaksanaan kegiatan ini. Terima kasih juga disampaikan kepada Kementerian Riset, Teknologi, dan Pendidikan Tinggi, Direktorat Jenderal Penguatan Riset dan Pengembangan, Direktorat Riset dan Pengabdian Kepada Masyarakat atas dukungan pendanaan yang diberikan pada Tahun 2019 melalui skema Program Pengembangan Desa Mitra. Tak lupa juga kami sampaikan kepada Universitas Tanjungpura atas dukungan kepada Tim pelaksana hingga kegiatan ini dapat dilaksanakan dengan baik dan lancar.

\section{DAFTAR RUJUKAN}

Badan_Penelitian_Dan_Pengembangan_Perta nian. 2014. LAHAN GAMBUT INDONESIA: Pembentukan, Karakteristik, Dan Potensi Mendukung Ketahanan Pangan. Revisi, Ce. Jakarta, Indonesia: IAARD Press. https://www.google.com/url?sa=t\&rct=j\&q $=\&$ esrc $=s \&$ source $=$ web\& $c d=\& c a d=r j a \& u a$ $\mathrm{ct}=8 \&$ ved=2ahUKEwit7ZGe3t3sAhXI_XM BHTroANEQFjABegQIAxAC\&url=http\%3 A\%2F\%2Fnasih.staff.ugm.ac.id\%2Fwpcontent\%2Fuploads\%2FLahan-GambutIndonesia.-Pembentukan-Karakteristikdan-Potensi-Mendukung-KetahananPangan.2014.pdf\&usg=AOvVaw3rXcBc4a4VR89 SVspfrwEl.

Dohong, Alue et al. 2018. Modul Pelatihan Pembangunan Infrastruktur Pembasahan Gambut Sumur Bor Berbasis Masyarakat. Jakarta, Indonesia: Badan Restorasi gambut.

https://brg.go.id/wpcontent/uploads/2019/01/1b.-ISI_ModulPelatihan_SUMUR-BOR.pdf.

Herawati, Henny, Aji Ali Akbar, Dwi Farastika, and Azmeri. 2018. "Water Table Evaluation Post the Construction of Canal Blocks on Peatland in West Kalimantan , Indonesia." 03016: 1-8. https://www.matec-

conferences.org/articles/matecconf/abs/2 018/54/matecconf_icrmce2018_03016/m atecconf_icrmce2018_03016.html.

Herawati, Henny, Kartini, Tătang Abdurrahman, and Aji Ali Akbar. 2019. Pembasahan Gambut Secara Pratisipatif. Pontianak, Kalimantan Barat.

Suherman, Dadan, and Nyoman Sumawijaya. 2013. "MENGHILANGKAN WARNA DAN ZAT ORGANIK AIR GAMBUT DENGAN METODE KOAGULASI-FLOKULASI Removing Colour and Organic Content of Peat Water Using Coagulation and Floculoation Method In Basaltic Condition Dadan Suherman Dan Nyoman Sumawijaya." Jurnal RISET Geologi dan Pertambanhan 23(2): 127-39. https://core.ac.uk/download/pdf/2339023 21.pdf.

World_Bank_Group. 2015. "Krisis Kebakaran Dan - Asap Indonesia." https://www.worldbank.org/in/news/featur e/2015/12/01/indonesias-fire-and-hazecrisis. 